\title{
An experimental study of longitudinal velocity distribution at cross-over and bend section of a compound meandering channel
}

\author{
Md. S. M. Khan ${ }^{1}$, Md. Abdullah Al Amin 2, ", Md. Mafizur Rahman ${ }^{3}$, Sarder Rafee Musabbir ${ }^{4}$, \\ K. M. Julfikar Tareq
}

${ }^{1}$ Professor, Dept. of Water Resources Engineering, BUET, Dhaka, Bangladesh

${ }^{2}$ Assistant Engineer, Bangladesh Water Development Board, Dhaka, Bangladesh

${ }^{3}$ Professor, Dept. of Civil Engineering, BUET, Dhaka, Bangladesh

${ }^{4}$ Undergraduate Student, Dept. of Civil Engineering, BUET, Dhaka, Bangladesh

${ }^{5}$ Sub Divisional Engineer, Bangladesh Water Development Board, Dhaka, Bangladesh

\section{Email address:}

mostafakhan@wre.buet.ac.bd (Md. S. M. Khan), amin_01buet@yahoo.com (Md. A. A. Amin), mafizur@gmail.com (Md. Mafizur Rahman),julfikartareq@yahoo.com(K. M. Julfikar Tareq)

\section{To cite this article:}

Md. S. M. Khan, Md. Abdullah Al Amin, Md. Mafizur Rahman, Sarder Rafee Musabbir, K. M. Julfikar Tareq. An Experimental Study of Longitudinal Velocity Distribution at Cross-over and Bend Section of a Compound Meandering Channel. American Journal of Civil Engineering. Vol. 1, No. 3, 2013, pp. 124-128. doi: 10.11648/j.ajce.20130103.16

\begin{abstract}
Generally, river flow can be schematized as compound meandering channel in which the longitudinal velocity distributions in the crossover and bend section are completely different and quite intricate. Engineers, Planners and Researchers are highly interested in predicting accurately as well as estimating quantitatively and reliably the longitudinal velocity distribution in a compound meandering channel. A laboratory experiment has been conducted in a compound meandering channel with symmetric cross-sections having floodplain width ratios $(\mathrm{B} / \mathrm{b})$ of $1.00,1.67,2.33,3.00$ and depth ratios $(\mathrm{H}-\mathrm{h}) / \mathrm{h}$ of $0.20,0.30,0.35,0.40$ using the large-scale open air facility in the Department of Water Resources Engineering, Bangladesh University of Engineering and Technology (BUET), Dhaka. Point velocity data have been collected using an ADV (Acoustic Doppler Velocity Meter) for different depth and width ratio at five different locations of a compound meandering channel. The traditional power law represents a vertical distribution of longitudinal velocity in open channel with maximum value at free surface and with zero at the channel bed. But the velocity distribution in the type of natural or laboratory compound meandering channel does not follow such velocity distribution. The longitudinal velocity distribution of a compound meandering channel shows two characteristics for all cases and depth ratios. In the bend section, velocity increases in the inner bend (convex) and decreases in the outer bend (concave). Similar nature is observed in the floodplain boundary for all cases and depth ratios. In the crossover of a compound meandering channel, velocity increases towards the mid-section and decreases in the boundary of the channel.
\end{abstract}

Keywords: Acoustic Doppler Velocity Meter, Depth Ratio, Flood Plain, Meandering Channel, Velocity Distribution, Width Ratio

\section{Introduction}

Most of the rivers have their cross sectional geometry in the form of a compound meandering channel section where a deep main channel is often flanked by one or two shallow adjacent floodplains. Generally, natural rivers, streams and manmade surface drainage channels often overflow their banks during episodes of high flooding resulting in a huge potential damage to life and property as well as erosion and depositions of sediments. It has been established that a strong interaction between the faster moving main channel flow and slower moving floodplain flow takes place in a compound channel. This interaction results in a lateral transfer of a significant amount of longitudinal momentum which affects the longitudinal velocity distribution in a channel flow. Velocity distribution in the main channel and floodplain in a compound meandering channels are different due to prevailing of different hydraulic conditions in the main channel and floodplain flow. Besides, there is 
also a wide variation in the longitudinal velocity distribution from the inner to the outer bank of a compound meandering channel section.

Longitudinal velocity distribution at bend and crossover section in a compound meandering channel is crucial in controlling floods, solving a variety of river hydraulics and engineering problems, designing stable channels, revetments and artificial waterways. There are limited reports concerning the velocity distribution in a compound meandering channel. Most of the efforts of [1],[2],[3], [4], [5], [6],[7],[8],[9],[10] and [11] were concentrated on the energy loss, conveyance, or the stage-discharge relationship, shear stress distribution of meandering compound sections. To the knowledge of the writer there are only a few reports available [12], [13], [14], [15] and [16] that describe the distribution of velocity in meandering compound channels. The present study is intended to understand the variation of longitudinal velocity distribution at bend and crossover section in a compound meandering channel for different depth and width ratios.

\section{Methodology}

The experimental study has been conducted in the open air facility of Water Resources Engineering Department, Bangladesh University of Engineering and Technology (BUET), Dhaka. The experimental setup is shown in Fig.1 which consists of two parts, the permanent part and the temporary part. The permanent part is the experimental facility necessary for the storage and regulation of water circulating through the experimental reach. The temporary part is mainly brick walls which are used to vary the floodplain width for different setups. The experimental reach consists of a $670 \mathrm{~cm}$ long symmetric compound meandering channel set at constant bed slope (So) 0.001845 with fixed bed and banks and the sinuosity ratio (Sr) of 1.20.Water is drawn by the centrifugal pump of discharge capacity $80 \mathrm{l} / \mathrm{s}$ from the storage reservoir, then it discharges into the $\mathrm{u} / \mathrm{s}$ reservoir and coveys water to the experimental reach through approach channel of $30 \mathrm{~m}$ in length and $3.1 \mathrm{~m}$ in width. To ensure a more smooth flow towards the approach channel guide vanes and tubes are placed between the upstream reservoir and the approach channel which are at right angle to each other. In order to prevent turbulence in the approach channel, PVC pipes (Diffuser) are used. The water regulating function of the downstream end is provided by tail gate. The tail gate rotates around a horizontal axis. It is operated to maintain desired water level in the experimental reach. At the end of the experimental channel, water is allowed to flow freely so that backwater has no effect in the experimental reach. Behind the tail gate, the water falls into the stilling basin and passes through a transition flume which allows water for recirculation

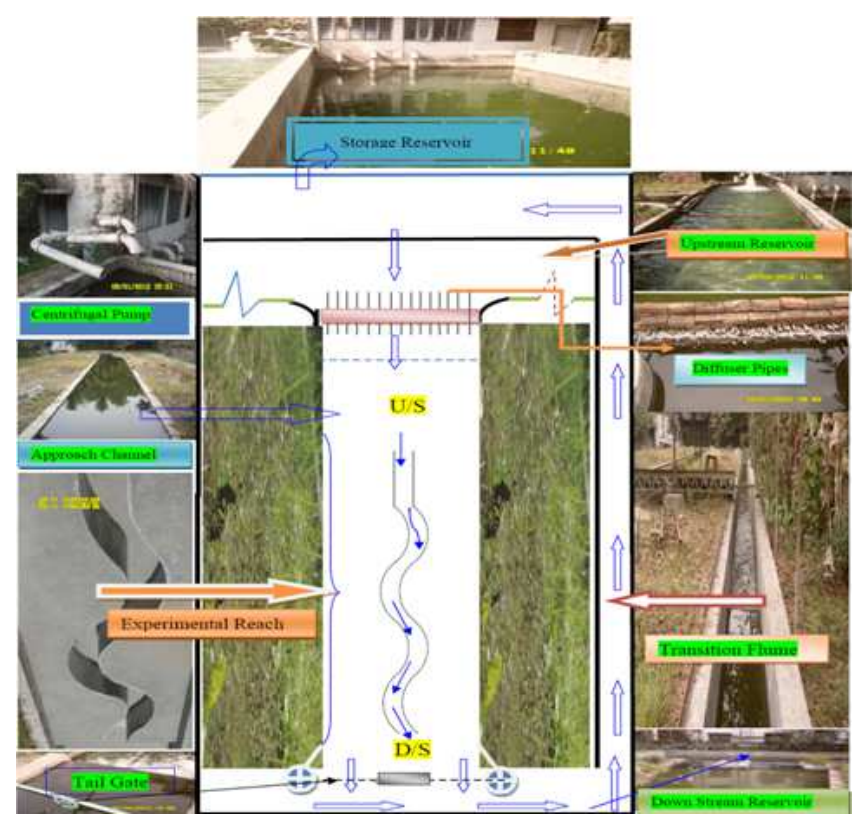

Figure 1. Schematic diagram of the laboratory experimental setup

Experiments were performed for four cases i.e. width ratio $1,1.67,2.33,3$ at four runs i.e. depth ratio $\mathrm{Dr}=0.2,0.3$, $0.35,0.4$.

Case I: It represents no floodplain condition having width ratio $\mathrm{Wr}=1$ and cross-sectional dimension of the Channel is $45.7 \mathrm{~cm} 42 \mathrm{~cm}$.

Case II: It indicates symmetric floodplain width $15.3 \mathrm{~cm}$ having width ratio $\mathrm{Wr}=1.67$. The cross-sectional dimension of the main channel is $45.7 \mathrm{~cm} \times 24.5 \mathrm{~cm}$, left floodplain $15.3 \mathrm{~cm} \times 18 \mathrm{~cm}$ and right floodplain $15.3 \mathrm{~cm} \times 18 \mathrm{~cm}$.

Case III: It indicates symmetric floodplain width $30.5 \mathrm{~cm}$ having width ratio $\mathrm{Wr}=2.33$. The cross-sectional dimension of the main channel is $45.7 \mathrm{~cm} \times 24.5 \mathrm{~cm}$, left floodplain $30.5 \mathrm{~cm} \times 18 \mathrm{~cm}$ and right floodplain $30.5 \mathrm{~cm} \times 18 \mathrm{~cm}$.

Case IV: It indicates symmetric floodplain width 45.70 $\mathrm{cm}$ having width ratio $\mathrm{Wr}=3$. The cross-sectional dimension of the main channel is $45.7 \mathrm{~cm} \times 24.5 \mathrm{~cm}$, left floodplain $45.7 \mathrm{~cm} \times 18 \mathrm{~cm}$ and right floodplain $45.7 \mathrm{~cm} \times 18 \mathrm{~cm}$.

Point velocities data have been collected by ADV (Acoustic Doppler Velocity meter) at different locations $(\mathrm{u} / \mathrm{s}$ clockwise bend, $\mathrm{u} / \mathrm{s}$ crossover, $\mathrm{u} / \mathrm{s}$ anticlockwise bend etc.) of a compound meandering channel. Each location is divided into 19 zones starting from left floodplain to right floodplain. The main channel is equally divided into nine zones (zone 1 to zone9), the left floodplain is equally divided into 5 zones (zone1 to zone5) and right floodplain is divided into 5 zones (zone1 to zone5) that are shown in Fig 2. In each zone $3 \mathrm{D}$ point velocity readings are taken by $\mathrm{ADV}$ at five vertical points i.e. $0.1 \mathrm{H}, 0.2 \mathrm{H}, 0.4 \mathrm{H}, 0.6 \mathrm{H}$, $0.8 \mathrm{H}$ for main channel and $0.1 \mathrm{H}^{\prime}, 0.2 \mathrm{H}^{\prime}, 0.4 \mathrm{H}^{\prime}, 0.6 \mathrm{H}^{\prime}, 0.8 \mathrm{H}^{\prime}$ for floodplain. In each vertical point 60 seconds point velocity readings are taken and average velocity of 60 seconds point velocity is used for plotting the velocity profile. The experimental run conditions are shown in the table 1 and the definition sketch of compound meandering 
channel is shown in Fig 2.

Table 1. Experimental run conditions

\begin{tabular}{ccccl}
\hline Case & Run no. & $\begin{array}{c}\text { Width } \\
\text { Ratio } \\
\text { (Wr) }\end{array}$ & $\begin{array}{c}\text { Depth } \\
\text { Ratio } \\
\text { (Dr) }\end{array}$ & Location of the Reading \\
\hline \multirow{4}{*}{ I } & 1 & & 0.20 & \\
& 2 & 1.00 & 0.30 & \\
& 3 & & 0.35 & \\
& 4 & & 0.40 & \\
II & 5 & & 0.20 & Velocity reading at $0.1 \mathrm{H}$, \\
& 6 & 1.67 & 0.30 & $0.2 \mathrm{H}, 0.4 \mathrm{H}, 0.6 \mathrm{H}, 0.8 \mathrm{H}$ from \\
& 7 & & 0.35 & the water surface in the main \\
& 8 & & 0.40 & channel and \\
III & 9 & & 0.20 & $0.1 \mathrm{H}^{\prime}, \quad 0.2 \mathrm{H}, \quad 0.4 \mathrm{H}^{\prime}, 0.6 \mathrm{H}^{\prime}$, \\
& 10 & 2.33 & 0.30 & $0.8 \mathrm{H}^{\prime}$ from the water surface \\
& 11 & & 0.35 & in the flood plain \\
& 12 & & 0.40 & \\
IV & 13 & & 0.20 & \\
& 14 & \multirow{2}{*}{3.00} & 0.30 & \\
& 15 & & 0.35 & \\
& 16 & & 0.40 & \\
\hline
\end{tabular}

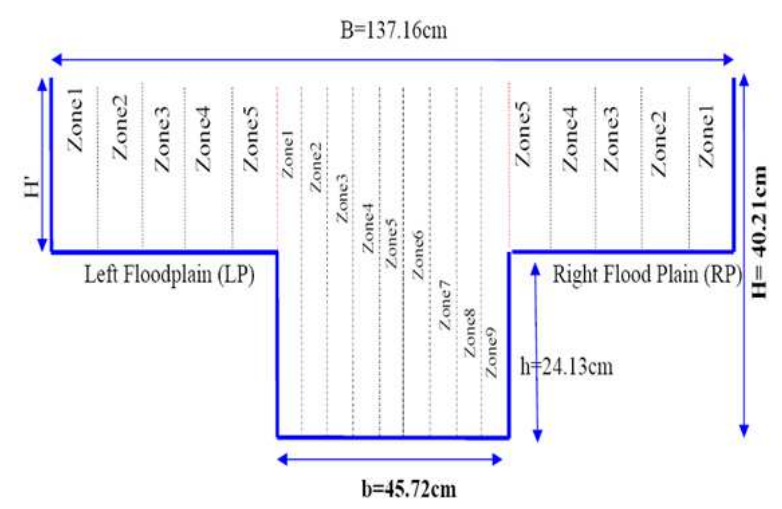

Figure 2. Sketch of the compound meandering channel section

\section{Results and Discussions}

Longitudinal velocity distribution in a compound meandering channel is affected by many factors such as width ratio, depth ratio, roughness of the channel, geometry of the channel, presence of bends etc. Here longitudinal velocity distribution at bend and crossover section with respect to width ratio and depth ratio are analyzed. The velocity profile at bend and crossover section for width ratio 1 , width ratio 1.67 , width ratio 2.33 , width ratio 3 are represented in the Fig. 3, Fig. 4, Fig. 5, Fig. 6, Fig. 7, Fig. 8 and Fig. 9 respectively. From the observation of velocity profiles and isovels for all cases and depth ratio, it is shown that in the bend section velocity increases in the inner bend and decreases in the outer bend. In addition to maximum and minimum velocity is obtained nearest to the inner and outer bend respectively in the bend section of a compound meandering channel. Because in the inner bend flow accelerate i.e. surface wind friction does not dominate and no secondary current is developed but in the outer bend flow decelerate i.e. surface wind resistance dominates intensively and secondary current is developed. In the crossover section, velocity increases in the mid-section of a channel and maximum velocity is occurred nearest to the mid-section of the channel.

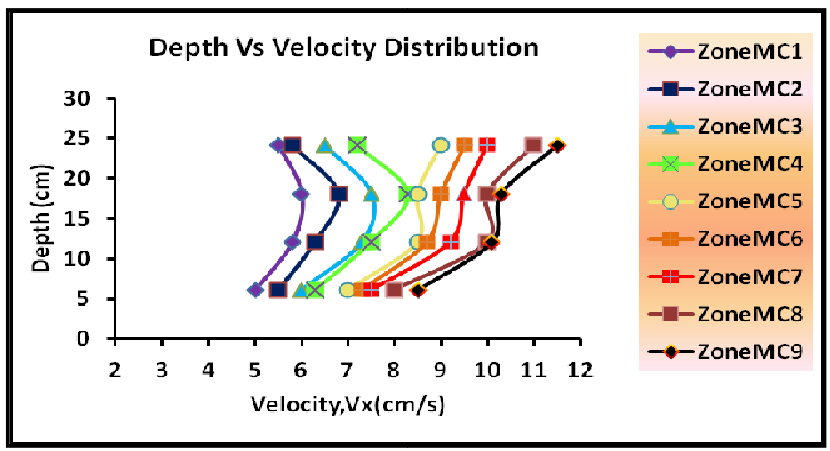

Figure 3. U/S Clockwise bend section for $W r=1, D r=0.40$

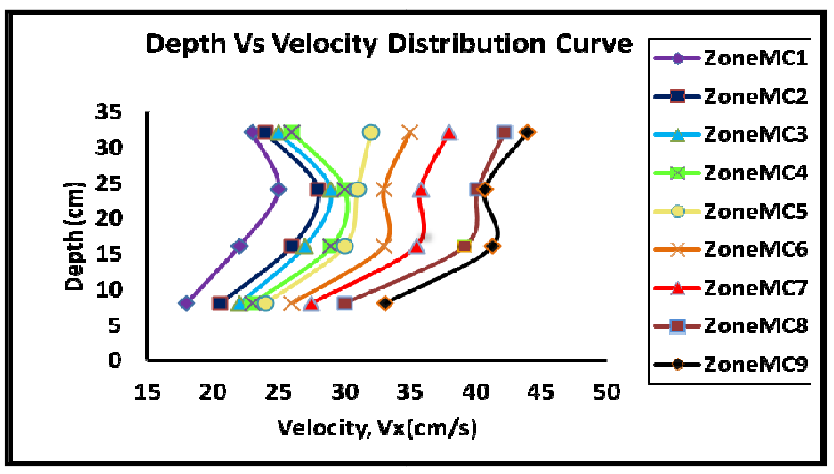

Figure 4. U/S Crossover section for $\mathrm{Wr}=1, \mathrm{Dr}=0.40$

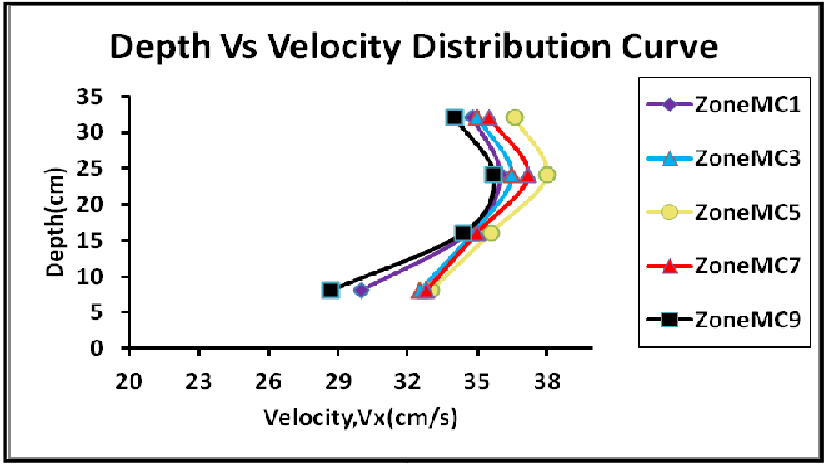

Figure 5. U/S Clockwise bend section for $W r=1.67, D r=0.20$

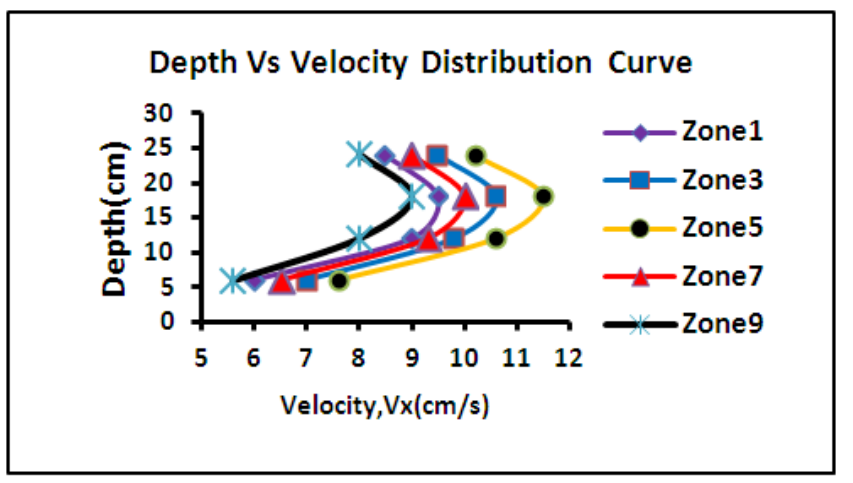

Figure 6. U/S Crossover section for $W r=1.67, D r=0.20$ 


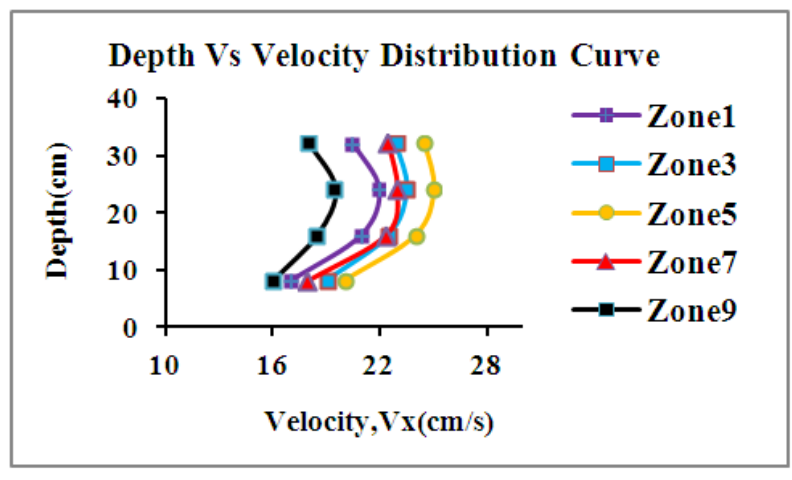

Figure 7. U/S Clockwise bend section for $W r=2.33, D r=0.40$

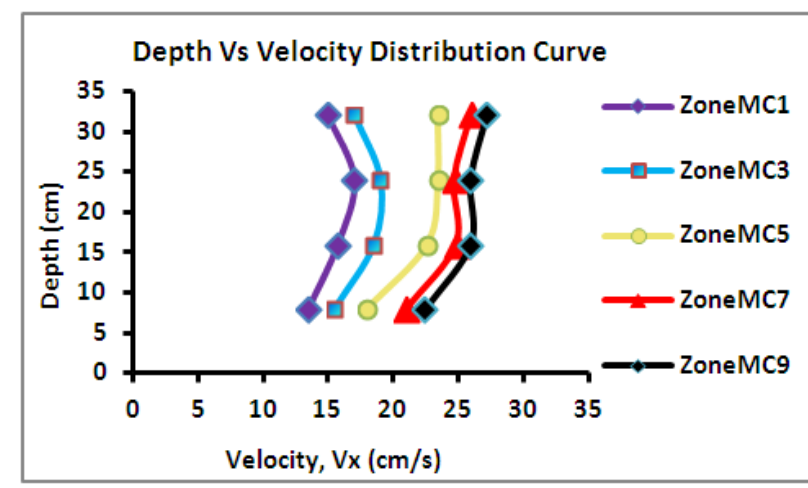

Figure 8. U/S Crossover section for $W r=2.33$, Dr $=0.40$

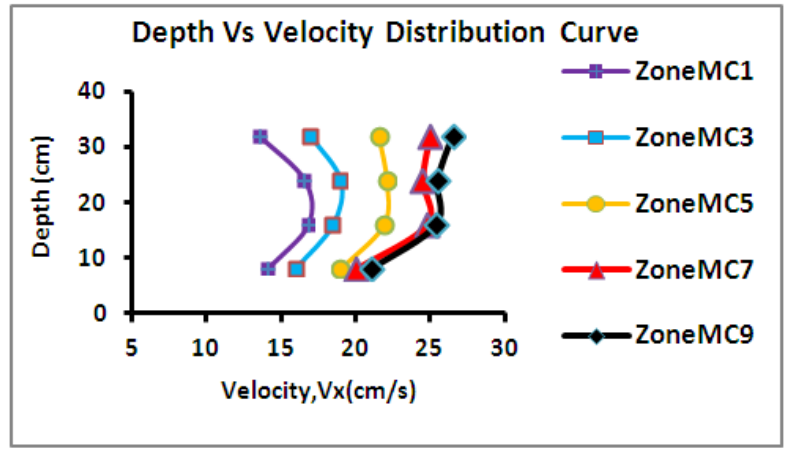

Figure 9. U/S Clockwise bend section for $W r=3.00, D r=0.40$

\section{Conclusions}

On the basis of present research concerning the longitudinal velocity distribution at cross-over and bend section of a compound meandering channel with varying floodplain width the following conclusions are drawn:

- In the bend section of a compound meandering channel longitudinal velocity increases in the inner bend and decreases in the outer bend. Maximum, minimum and average longitudinal velocity is occurred nearest to the inner bend, outer bend and mid-section respectively of a compound meandering channel.

- In the crossover section of a compound meandering channel, longitudinal velocity increases in the mid of the section and maximum velocity is resulted nearest to the mid-section of a channel.
- The longitudinal velocity profile of a compound meandering channel shows two shapes. In the bend section of a compound meandering channel, velocity profile follows logarithmic distribution in the inner bend and natural channel velocity distribution in the outer bend.

- In the crossover section of a compound meandering channel, longitudinal velocity distribution is similar to the natural channel velocity distribution.

It is recommended that further investigation be focused on extending the present analysis to the compound meandering channel of unsymmetrical cross sections with different floodplain width.

\section{Acknowledgements}

First of all, the authors are very much thankful to the almighty, Allah for enabling them to complete their work successfully. The authors convey their sincere gratitude to head of the Department of Water Resources Engineering, Bangladesh University of Engineering and Technology, for giving all the facilities needed which helped the authors to reach at culmination of the work successfully. The authors would like to thank the assistants of Physical Modelling Laboratory of BUET for their dexterous help to complete their laboratory experiment efficiently.

Finally, the authors would like to thank all of their well wishers and colleagues.

\section{Nomenclature}

The following symbols are used in this paper

$\mathrm{B}=$ top width of compound meandering channel

$\mathrm{b}=$ width of main channel

$\mathrm{Dr}=$ depth ratio $(\mathrm{H}-\mathrm{h}) / \mathrm{h}$

$\mathrm{H}=$ total water depth

$\mathrm{H}^{\prime}=$ depth of water above floodplain bed

$\mathrm{h}=$ height of the main channel

$\mathrm{S}_{\mathrm{o}}=$ bed slope

$\mathrm{S}_{\mathrm{r}}=$ sinuosity ratio

$\mathrm{U}=$ mean velocity

$\mathrm{Wr}=$ width ratio $[\mathrm{B} / \mathrm{b}]$

\section{References}

[1] Toebes, G. H., and Sooky, A. A. (1967). "Hydraulics of meandering rivers with flood plains." J. Waterw. Harbors Div., Am. Soc. Civ. Eng., 93(2), 213-236.

[2] Greenhill, R. K., and Sellin, R. H. J. (1993). “Development of a simple method to predict discharge in compound meandering channels." Proc. Institute Civil Engineers, Water, Merit and Energy, 101, Water Board, (March), $37-44$.

[3] Sellin, R. H. J., Ervine, D. A., and Willetts, B. B. (1993). "Behavior of meandering two stage channels." Proc. of Institute Civil Engineers Water Maritime and Energy, 101, (June), Paper No. 10106, 99-111. 
[4] Willetts, B. B., and Hardwick, R. I. (1993). "Stage dependency for over bank flow in meandering channels." Proc., Institute of Civil Engineers Water Maritime and Energy, 101, 45-54.

[5] Wark, J. B., and James, C. S. (1994). “An application of new procedure for estimating discharge in meandering overbank flows to field data." 2nd Int. Conf. on River Flood Hydraulics, March 22-25, Wiley, NewYork, 405-414.

[6] Shiono, K., Muto, Y., Knight, D. W., and Hyde, A. F. L. (1999a). "Energy losses due to secondary flow and turbulence in meandering channels with over bank flow." J. Hydraul. Res., 37(5), 641-664.

[7] Patra, K. C., and Kar, S. K. (2000). "Flow interaction of meandering river with floodplains." Journal of Hydraulic Engineering, ASCE, 126(8), 593-604.

[8] Khatua, K. K., and Patra, K.C. (2007). " Boundary shear stress distribution in compound open channel flow.” Journal of Hydraulic Engineering, ISH, 12(3), 39-55.

[9] Khatua, K. K.(2008). "Interaction of flow and estimation of discharge in two stage meandering compound channels.'Ph.D. thesis, NIT, Rourkela, India.

[10] Mohanty, K. P., Das, S. S., and Khatua, K. K. (2012). "Flow investigations in a wide meandering compound channel." International Journal of Hydraulic Engineering, 1(6), 83-94.
[11] Amin, M. A. A., Khan, M. S. M., and Islam, M. A. U. (2013). "An experimental study of shear stress distribution in a compound meandering channel."American Journal of Civil Engineering, 1(1), 1-5.

[12] Shiono, K., and Muto, Y. (1993). "Secondary flow structure for inbank and overbank flows in trapezoidal meandering channels." Proc., 5th Int. Symp. of Refined Flow Modl. and Turb. Measu., Paris (September), 645-652.

[13] Muto, Y. (1995). "Turbulent flow in two stage meander chanenls." PhD thesis, Univ. of Bradford, U.K.

[14] Morvan, H., Pender, G., Wright, N. G., and Ervine, D. A. (2002). "Three-Dimensional Hydrodynamics of Meandering Compound Channels." Journal of Hydraulic Engineering, ASCE, 128(7), 674-682.

[15] Patra, K.C., and Kar, S.K., Bhattacharya.A.K. (2004). "Flow and Velocity Distribution in Meandering Compound Channels." Journal of Hydraulic Engineering, ASCE, Vol. 130, No. 5. 398-411.

[16] Khatua, K. K., Patra, K. C., Sahoo, N. and Nayak, P. P. (2010). "Evaluation of Boundary Shear in a Meandering Channel." Proceedings of Ninth ICHE, IIT Madras,Chennai,India. 